\title{
Palladium-Catalyzed Arylation and Heteroarylation of Indolizines
}

\author{
Choul-Hong Park, Victoria Ryabova, llya V. Seregin, Anna W. Sromek, and Vladimir \\ Gevorgyan \\ Department of Chemistry, University of Illinois at Chicago, 845 W. Taylor St., Chicago, Illinois \\ 60607-7061
}

Vladimir Gevorgyan: vlad@uic.edu

\section{Abstract}

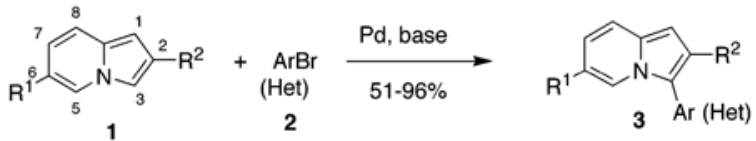

A highly effective protocol for palladium-catalyzed selective arylation and heteroarylation of indolizines at C-3 has been developed. Mechanistic studies unambiguously support an electrophilic substitution pathway for this transformation.

Indolizines substituted at C-3 are very attractive heterocyclic units, as a number of representatives of this class ${ }^{1}$ and, especially their partially or completely reduced analogues, indolizidine alkaloids ${ }^{2}$ and related unnatural compounds, ${ }^{3}$ exhibit important biological properties. As a part of our program on developing efficient methods toward differently substituted indolizines, we were particularly interested in elaborating efficient approaches toward C-3-arylated indolizines. To date, no general convenient methods for synthesis of C-3-arylated indolizines exist. ${ }^{4}$ Scattered reports on synthesis of C-3-arylated indolizines via various modes of Chichibabin-type cyclocondensation ${ }^{5}$ are limited to particular substitution patterns ${ }^{6}$ and generally provide low to moderate yields of the products. ${ }^{7}$ Other methods such as dipolar cycloaddition of pyridinium ylides with alkynes, ${ }^{8}$ cyclopropenones, ${ }^{9}$ or cyclopropenes ${ }^{10}$ are limited to use of symmetric substrates, producing indolizines with two identical substituents at the pyrrole ring. Finally, synthesis of indolizines via cycloisomerization of alkynyl pyridines, ${ }^{11,12}$ a method recently developed within our group, potentially can give access to 3-arylindolizines; however, it would require employment of rather expensive 3-aryl-1-propynes and, in this case, is unlikely to be considered as synthetically useful. Thus, we decided to explore the possibility of direct, last-stage methods of arylation of the indolizine core. Although analogous reactions on various heterocyclic systems such as furans, ${ }^{13}$ thiophenes, ${ }^{13 a}, 14$ pyrroles, ${ }^{15}$ and indoles ${ }^{16}$ have long been known, no reports on arylations involving indolizines have been reported to date. ${ }^{17}$ Herein we report efficient palladium-catalyzed arylation and heteroarylation of indolizines, which allows for selective incorporation of aromatic or heteroaromatic substituent at the C-3 position of this heterocycle.

Initial experiments revealed that indolizine 1a indeed underwent arylation in the presence of different palladium sources in DMSO; however, a 3-fold excess with respect to arylbromide

(C) 2004 American Chemical Society

Correspondence to: Vladimir Gevorgyan, vladeuic. edu.

Supporting Information Available: Detailed experimental procedures for preparation of and spectroscopic data for compounds 3aa-ed and 10. This material is available free of charge via the Internet at http://pubs.acs.org. 
was required to attain high yields, and the reaction was rather sluggish, as it took 2 days for completion. Optimization experiments ${ }^{18}$ indicated that arylation of indolizines proceeded much faster (1-3 h) in the presence of catalytic amounts of $\mathrm{PdCl}_{2}\left(\mathrm{PPh}_{3}\right)_{2}, \mathrm{KOAc}$ (2 equiv), and $\mathrm{H}_{2} \mathrm{O}$ (2 equiv) in NMP at $100{ }^{\circ} \mathrm{C}$. Under these reaction conditions, a variety of differently substituted indolizines 1 underwent smooth arylation with an equimolar amount of $\mathbf{2}$ to afford C-3-arylated products $\mathbf{3}$ in good to excellent yields (Table 1). A variety of substituents are tolerated both on the indolizine and aryl halide. Nitro phenyl bromide $\mathbf{2 a}$ reacted efficiently with all indolizines tested (Table 1, entries 1, 3, 5, 6, and 9). Notably, electron-rich bromoanisole $\mathbf{2 c}$ underwent cross-coupling with both 2-cyanoindolizine $\mathbf{1 b}$ and 2-methylindolizine 1d (entries 4 and 8). Most remarkably, naphthyl bromide $2 \mathbf{d}$ and even bromothiophene $\mathbf{2 e}$ were able to undergo cross-coupling with 1e to produce naphthyl- and hetaryl-substituted indolizines 3ec and 3ed in reasonable yields (entries 11 and 12).

Naturally, we were interested in elucidating the mechanism for this arylation reaction. Different mechanisms, depending on substitution patterns and reaction conditions, have been proposed for analogous arylations of other heterocycles (vide infra). We were particularly intrigued by Sharp's recent report on the regioselective Heck arylation of 3ester-substituted furans and thiophenes (Scheme 1). ${ }^{13 a}$ It occurred to us that arylation of indolizines 1a-c, possessing EWG at C-2, and thus resembling Sharp's substrate 4, may potentially proceed via a similar Heck-type process. Thus, we attempted a cascade Heck reaction $^{19}$ of $\mathbf{1 f}$, aiming for spirocyclic compound $\mathbf{5}$ (Scheme 2). If successful, this process would not only bring firm support for the involvement of a Heck-type mechanism but also allow for straightforward access to polycyclic, indolizine-containing heteroaromatic compounds. However, trials on this cascade transformation with allyl ether $\mathbf{1 f}$ were unsuccessful, producing a mixture of arylated indolizines 6 and 7 instead (Scheme 2). We also attempted to perform a reductive Heck reaction ${ }^{20}$ on $\mathbf{1 a}$ toward dihydroindolizine derivative $\mathbf{8}$ (Scheme 2). However, numerous efforts to perform this transformation under a variety of reducing conditions failed. We also attempted the arylation of 6-

carboethoxyindolizine 1g, expecting to obtain the product of the Heck reaction, indolizine 9 (Scheme 2). To our surprise, however, $1 \mathrm{~g}$ was selectively arylated at C-3 instead, producing $\mathbf{1 0}$ as a single regioisomer.

Failure to obtain any support for involvement of the Heck-type protocol in the arylation of indolizines prompted us to consider alternative mechanistic routes for this reaction.

Different pathways proposed for arylation of various heterocycles, which can be adopted for arylation of indolizines, are depicted in Scheme 3. In addition to the Heck mechanism $(\mathbf{A})^{21}$ discussed above, several other pathways have been suggested.

C-H activation motif $\mathbf{B}$ has been proposed by Miura for the "coordination-assisted" C-3 arylation of 2-carbamoyl-substituted thiophenes ${ }^{14 a}$ and also by Sames as a possible route for arylation of unsubstituted indoles. ${ }^{15}$ To elucidate possible involvement of $\mathrm{C}-\mathrm{H}$ activation (path B) in the Pd-catalyzed arylation of indolizines, a kinetic isotope effect study was performed (Scheme 4). We subjected deuteriumlabeled 2-carboethoxyindolizine 1a to our arylation conditions. If $\mathrm{C}-\mathrm{H}$ activation path $\mathbf{B}$ is in operation, a substantial isotope effect would be expected. ${ }^{22}$

Experiments revealed, however, no isotope effect $\left(k_{\mathrm{H} / \mathrm{D}}=1\right)$, thus disfavoring possible involvement of pathway $\mathbf{B}$.

Another related mechanism, cross-coupling pathway $\mathbf{C}$, has been proposed by Miura ${ }^{23}$ and Sames $^{24}$ for the copper-assisted C-2 arylation of azoles. Thus, we looked at cross-coupling (path $\mathbf{C}$ ) as a possible route for our arylation reaction. Since it has been reported that arylation of acidic sites of the heterocycles is promoted by the addition of $\mathrm{Cu}$ salts, ${ }^{23,24}$ we 
attempted arylation of 1a in the presence of CuI. Contrary to our expectations, the presence of $\mathrm{CuI}$ greatly lengthened reaction times and reduced yields, thus disfavoring the involvement of mechanism $\mathbf{C}$.

The fourth possible mechanism (D), electrophilic aromatic substitution, was initially proposed by Miura ${ }^{23}$ and since then has often been considered as the most probable mechanism for arylation of heterocycles. ${ }^{13 a}, 15,17,25$ Accordingly, we drew our attention to mechanism D. Importantly, the absence of an isotope effect in the arylation of 1a, mentioned above (Scheme 4), does not contradict with electrophilic mechanism D. In this case, C-H cleavage is a fast step, ${ }^{26}$ and thus no isotope effect could be expected. Furthermore, it is generally believed that the pyrrole ring of indolizines is rather electron-rich, as it easily undergoes electrophilic substitution reactions. ${ }^{4}$ Our DFT calculations (B3LYP/6-31G*) perfectly confirmed this point, revealing that the pyrrole ring has an extended HOMO, whereas the LUMO mostly resides at the pyridine ring (Figure 1). Thus, it is quite reasonable that Pd-catalyzed electrophilic arylation selectively occurs at the electron-rich pyrrole ring. Similar arguments were provided by $\mathrm{Li}$ for the selective arylation of the imidazole ring in imidazopyrimidines. ${ }^{17}$ It is noteworthy that our calculations revealed that introduction of an EWG at C-6 of the pyridine ring does not qualitatively change the $\mathrm{HOMO} / \mathrm{LUMO}$ distribution, which perfectly explains arylation of $\mathbf{1 g}$ at the pyrrole ring to give 10 (Scheme 2).

Finally, to gain further support for electrophilic mechanism D, we performed kinetic studies. It was expected that electron-donating substituents at C-2 of indolizine would accelerate arylation at C-3, whereas electron-withdrawing groups should suppress the reaction. To test this hypothesis, competition experiments were run between indolizine (1e), 2methylindolizine (1d), and 2-carboethoxyindolizine (1a). The relative rates of Pd-catalyzed arylation (method $\mathbf{A}$ ) of 1e:1d:1a were found to be: 1.00:0.97:0.66. The EWG-substituted indolizine 1a underwent the slowest arylation, as expected; however, 2-methylindolizine 1d was arylated slightly more slowly than parent indolizine 1e. Potentially, this could be attributed to the steric bulk of the methyl group. To get a direct comparison of relative rates of Pd-catalyzed arylation with traditional Friedel-Crafts-type reactions, we set up electrophilic acylation of the same substrates with acyl chloride in the presence of $\mathrm{AlCl}_{3}$ (method B). Experiment revealed relative rates of C-3 acylation of 1e:1d:1a equal to 1:00:0.67:0.33. Although the values are not identical, the trend in rates for Friedel-Crafts acylation of indolizines reflects the trend in rates found for the Pd-catalyzed arylation reaction. We believe that these kinetic results, in combination with all experimental and computational data presented above, strongly support the electrophilic mechanism for the Pd-catalyzed arylation of indolizines.

In conclusion, the direct, efficient, regioselective C-3 aryl-and heteroarylation of indolizines has been developed. A variety of substituents on both the indolizine and aryl bromide are tolerated, providing rapid access to substituted indolizines in good to very high yields. Electrophilic substitution has been strongly supported as the mechanism through a combination of experimental and computational data.

\section{Supplementary Material}

Refer to Web version on PubMed Central for supplementary material.

\section{Acknowledgments}

We gratefully acknowledge the financial support of the National Institutes of Health (GM-64444). 


\section{References}

1. For recent examples, see: Sawada K, Okada S, Kuroda A, Watanabe S, Sawada Y, Tanaka H. Chem Pharm Bull. 2001; 49:799. [PubMed: 11456083] Ostby OB, Dalhus B, Gundersen LL, Rise F, Bast A, Haenen GRMM. Eur J Org Chem. 2000; 22:3763.

2. For recent reviews, see: Michael JP. Alkaloids. 2001; 55:91. [PubMed: 11704985] Michael JP. Nat Prod Rep. 2002; 19:742. [PubMed: 12521267]

3. See, for example: Halab L, Becker JAJ, Darula Z, Tourwe D, Kieffer BL, Simonin F, Lubell WD. J Med Chem. 2002; 45:5353. [PubMed: 12431062] Pearson WH, Hembre EJ. J Org Chem. 1996; 61:5546.

4. For a review on syntheses and properties of indolizines, see: Behnisch A, Behnisch P, Eggenweiler M, Wallenhorst T Indolizine. Houben-Weyl. 1994; E6b/1, 2a:323-450.

5. For original papers, see: Chichibabin AE. Chem Ber. 1927; 60B:1607.Chichibabin AE, Stepanov FN. Chem Ber. 1929; 62B:1068.

6. See, for example: Katritzky AR, Caster KC, Rubio O, Schwarz O. J Heterocycl Chem. 1986; 23:1315.

7. See, for example: Zhou J, Hu YF, Hu HW. Synthesis. 1999:166.

8. See, for example: Katritzky AR, Qui G, Yang B, He HY. J Org Chem. 1999; 64:7618.

9. See, for example: Wadsworth DH, Bender SL, Smith DL, Luss HR, Weidner CH. J Org Chem. 1986; 51:4639.Gundersen LL, Malterud KE, Negussie AH, Rise F, Teklu S, Ostby OB. Bioorg Med Chem. 2003; 11:5409. [PubMed: 14642585]

10. See, for example: Matsumoto K, Uchida K. J Chem Soc Perkin Trans. 1981; 1:73.

11. Kel'in AV, Sromek AW, Gevorgyan V. J Am Chem Soc. 2001; 123:2074. [PubMed: 11456838]

12. Kim JT, Gevorgyan V. Org Lett. 2002; 4:4697. [PubMed: 12489964]

13. (a) Glover B, Harvey KA, Liu B, Sharp MJ, Tymoschenko M. Org Lett. 2003; 5:301. [PubMed: 12556177] (b) McClure MS, Glover B, McSorley E, Millar A, Osterhout M, Roschangar F. Org Lett. 2001; 3:1677. [PubMed: 11405684]

14. (a) Okazawa T, Satoh T, Miura M, Nomura M. J Am Chem Soc. 2002; 124:5286. [PubMed: 11996567] (b) Lavenot L, Gozzi C, Ilg K, Orlova I, Pealva V, Lemaire M. J Organomet Chem. 1998; 567:49.(c) Gozzi C, Lavenot L, Ilg K, Penalva V, Lemaire M. Tetrahedron Lett. 1997; 38:8867.

15. Sezen B, Sames D. J Am Chem Soc. 2003; 125:5274. [PubMed: 12720429]

16. (a) Akita Y, Itagaki Y, Takizawa S, Ohta A. Chem Pharm Bull. 1989; 37:1477.(b) Itahara T. Chem Commun. 1981:254.(c) Akita Y, Inoue A, Yamamoto K, Ohta A. Heterocycles. 1985; 23:2327.

17. When our project was underway, a report on Pd-catalyzed arylation of imidazopyrimidines appeared; see: Li W, Nelson DP, Jensen MS, Hoerrner S, Javadi GJ, Cai D, Larsen RD. Org Lett. 2003; 5:4835. [PubMed: 14653686]

18. See Supporting Information for details.

19. Brase, S.; de Meijere, A. Handbook of Organopalladium Chemistry for Organic Synthesis. Negishi, E., editor. Vol. 1. John Wiley and Sons; New York: 2002. p. 1369-1404.

20. Brase, S.; de Meijere, A. Handbook of Organopalladium Chemistry for Organic Synthesis. Negishi, E., editor. Vol. 1. John Wiley and Sons; New York: 2002. p. 1405-1430.

21. For Heck arylation of furans, see: ref 13a. For Heck arylation of thiophenes, see: refs 13a and $14 \mathrm{~b}, \mathrm{c}$

22. Jones WD. Acc Chem Res. 2003; 36:140. [PubMed: 12589699]

23. Pivsa-Art S, Satoh T, Kawamura Y, Miura M, Nomura M. Bull Chem Soc Jpn. 1998; 71:467.

24. Sezen B, Sames D. J Am Chem Soc. 2003; 125:10580. [PubMed: 12940740]

25. Hughes CC, Trauner D. Angew Chem Int Ed. 2002; 41:1569. Erratum: Hughes CC, Trauner D. Angew Chem Int Ed. 2002; 41:2227.

26. Taylor, R. Electrophilic Aromatic Substitution. John Wiley and Sons; Chichester, UK: 1990. p. 25-57.

Org Lett. Author manuscript; available in PMC 2013 July 11. 


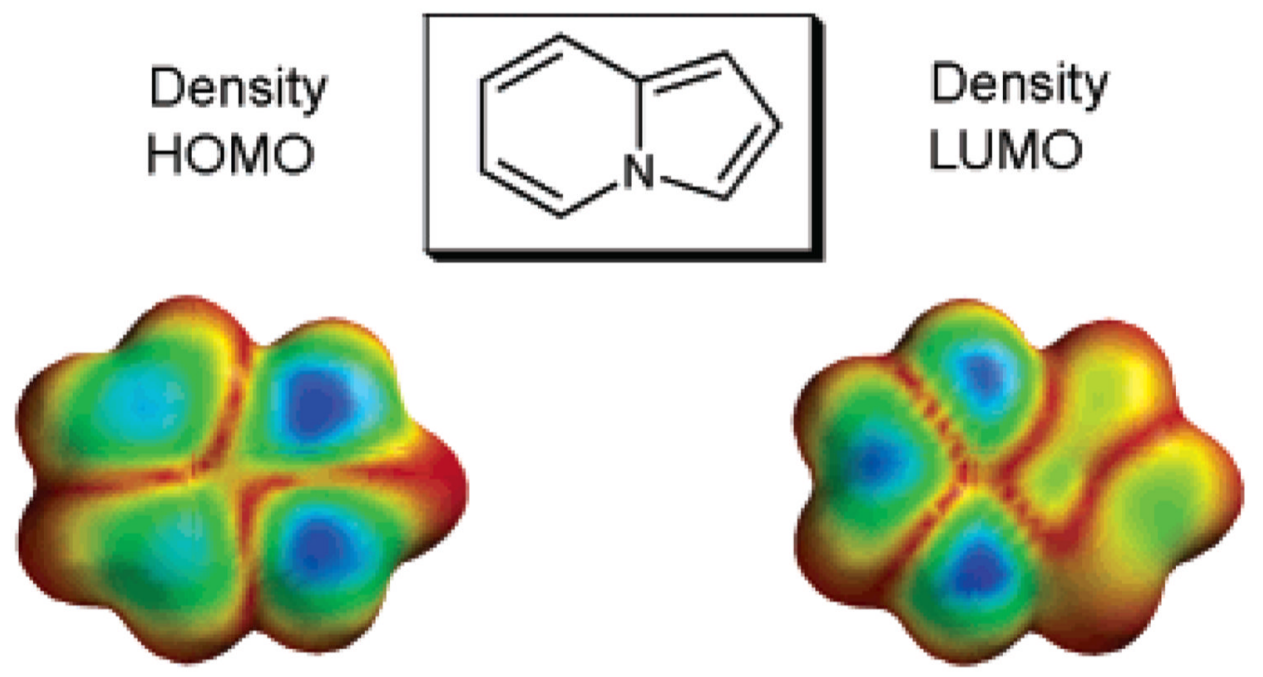

Figure 1.

HOMO and LUMO Densities of $1 \mathbf{e}$. 


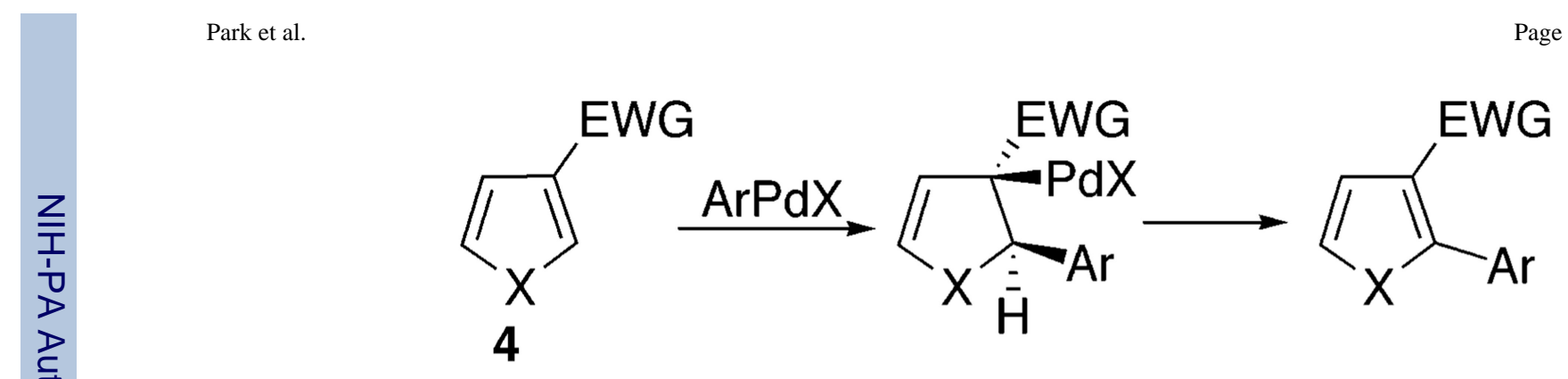

Scheme 1. Proposed Heck Arylation of Heterocycles ${ }^{13 a}$ 


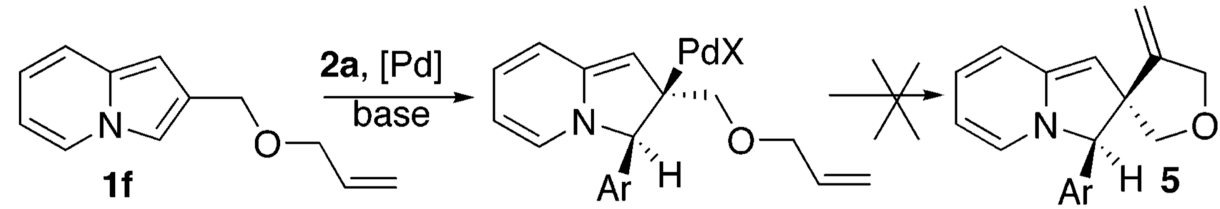<smiles>C=CCOCc1cc2ccc(CC)cn2c1Br</smiles>

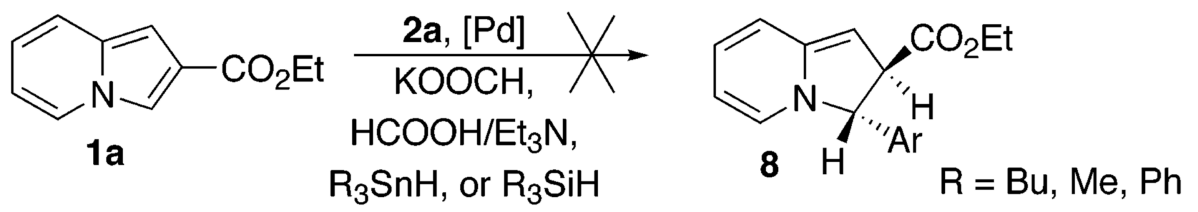<smiles></smiles>

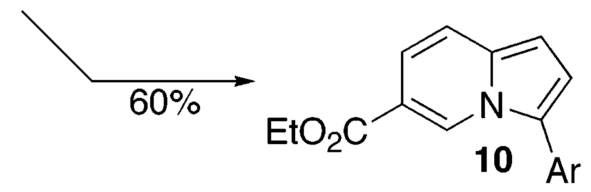

Scheme 2. Attempts to Perform Heck Reaction on Indolizines 


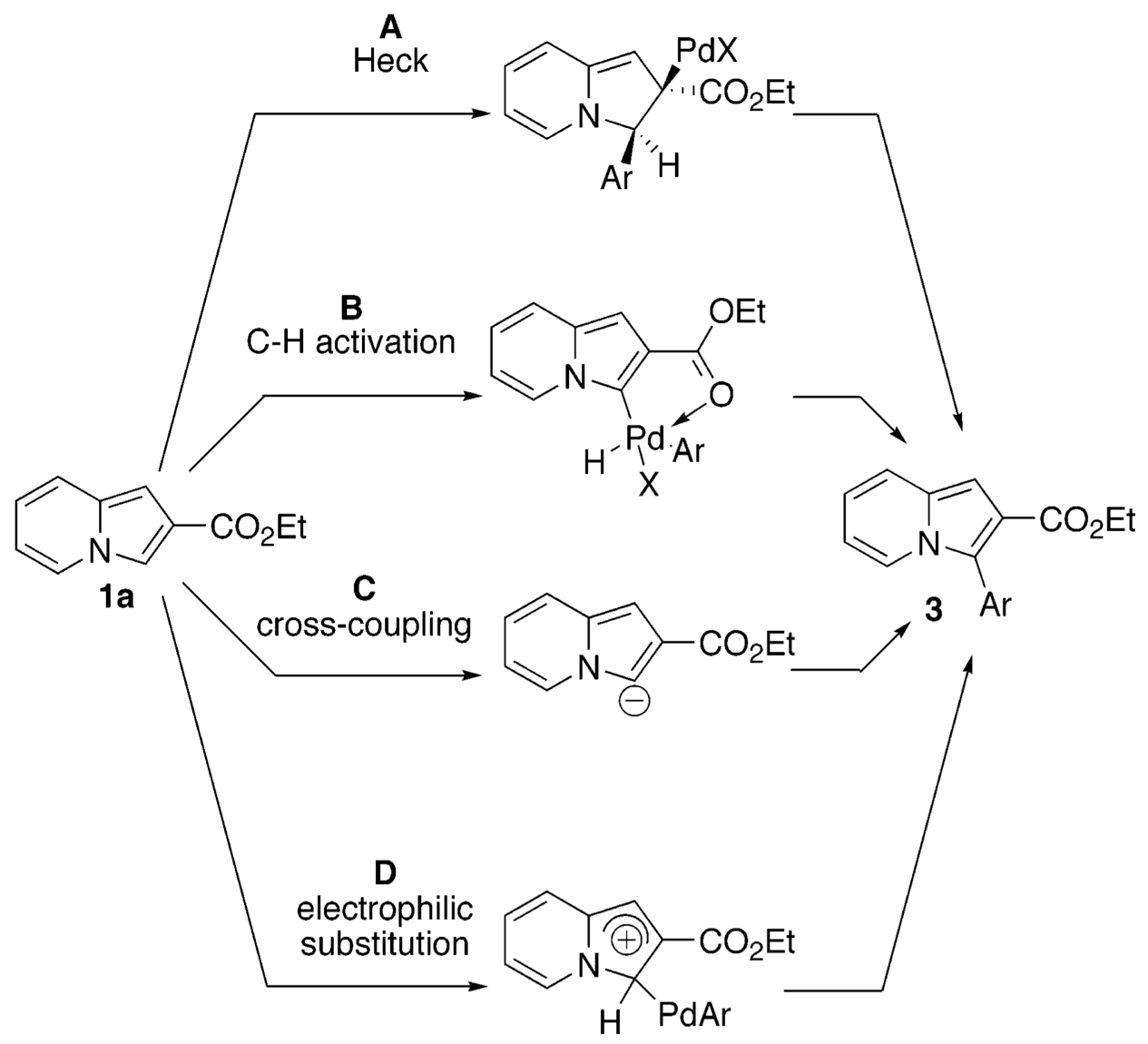

Scheme 3. Possible Mechanisms for Pd-Catalyzed Arylation of Indolizines 


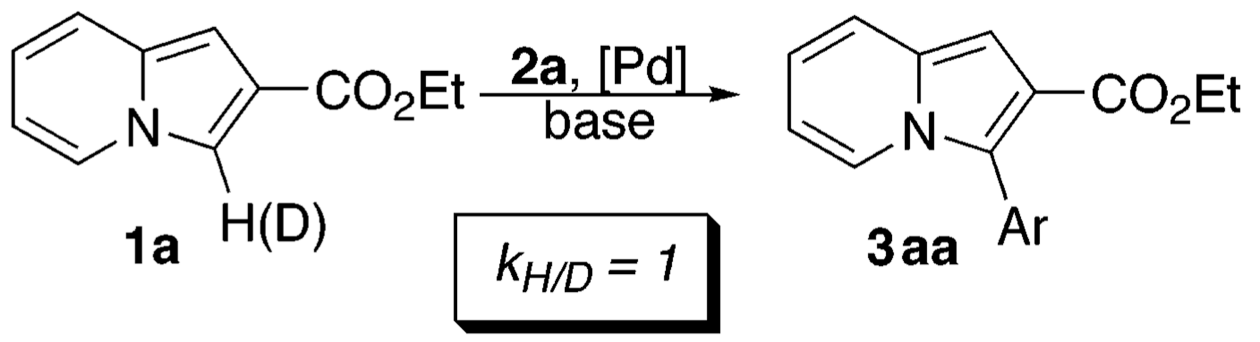

Scheme 4. Isotope Effect Study 
Table 1 Arylation and Heteroarylation of Indolizines 

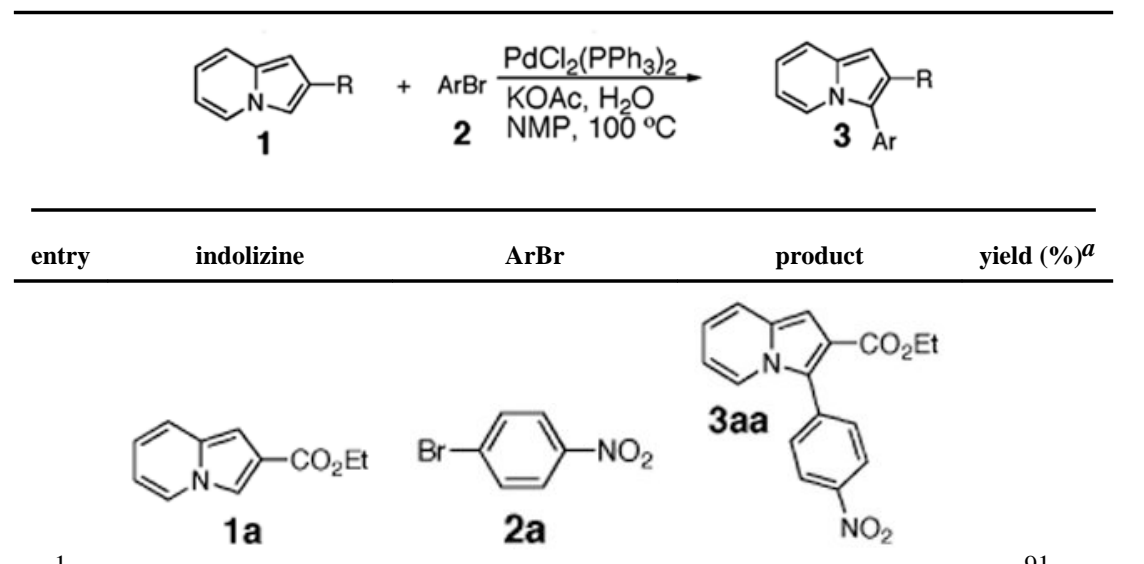<smiles>Brc1ccccc1</smiles><smiles>[18OH]</smiles><smiles>CCOC(=O)c1cc2ccccn2c1-c1ccccc1</smiles>

$1 a$<smiles>N#Cc1cc2ccccn2c1</smiles>

1b<smiles>O=[N+]([O-])c1ccc(Br)cc1</smiles>

2a

3

4

1b<smiles>COc1ccc(Br)cc1</smiles><smiles>COc1ccc(-c2c(C#N)cc3ccccn23)cc1</smiles>

51<smiles>CC(=O)c1cc2ccccn2c1</smiles><smiles>O=[N+]([O-])c1ccc(Br)cc1</smiles>

5<smiles>Cc1cc2ccccn2c1</smiles><smiles>O=[N+]([O-])c1ccc(Br)cc1</smiles><smiles>CC(=O)c1cc2ccccn2c1-c1ccc([O+])cc1</smiles>

82<smiles>Cc1ccc(-c2c(C)cc3ccccn23)cc1</smiles>

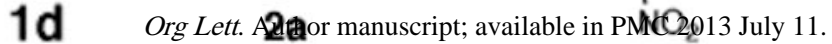<smiles>Cc1cc2ccccn2c1C(C)C</smiles> 
${ }^{a}$ Yields refer to pure isolated yields.

$b_{\text {NMR yield. }}$

${ }^{c}$ Reactions were run in NMP at $100{ }^{\circ} \mathrm{C}$ by using a $0.5 \mathrm{M}$ solution of $\mathbf{1}$ with the following molar ratio: $\mathbf{1}: \mathbf{2}: \mathrm{PdCl}_{2}\left(\mathrm{PPh}_{3}\right)_{2}: \mathrm{H}_{2} \mathrm{O}: \mathrm{KOAc}=$ 1:1.2:0.05:2:2. 
Table 2

Relative Rates of Pd-Catalyzed Arylation and Electrophilic Acylation of Selected Indolizines

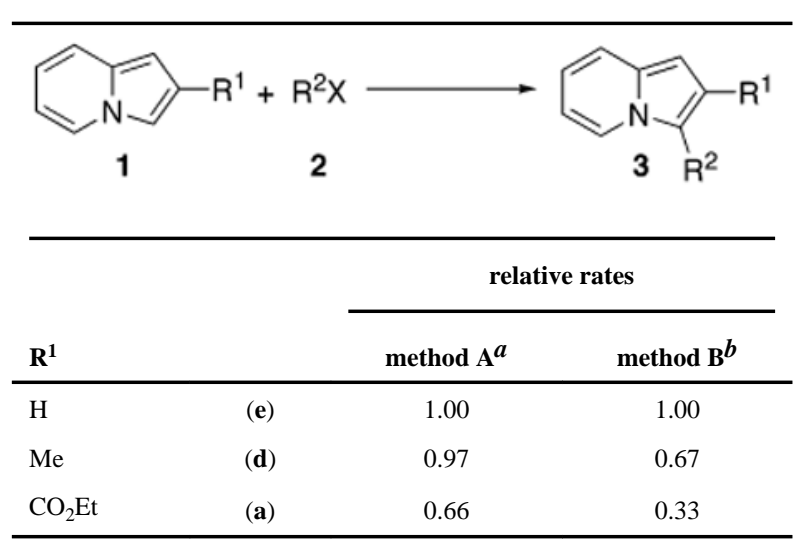

${ }^{a}$ Performed with $5 \% \mathrm{PdCl}_{2}\left(\mathrm{PPh}_{3}\right)_{2}, 2=0.75$ equiv of $p$ - $\mathrm{NO}_{2} \mathrm{C}_{6} \mathrm{H}_{4} \mathrm{Br}, \mathrm{KOAc}, \mathrm{H}_{2} \mathrm{O}$ in NMP, $100{ }^{\circ} \mathrm{C}$.

$b$ Performed with 1 equiv of $\mathrm{AlCl}_{3}, 2=0.75$ equiv of $\mathrm{AcCl}, \mathrm{CH}_{2} \mathrm{Cl}_{2},-78^{\circ} \mathrm{C}$. 